\title{
IMPACTO DO CONVÍVIO INTERGERACIONAL NA SOCIALIZAÇÃO DE IDOSAS INSTITUCIONALIZADAS
}

\section{ARTIGO ORIGINAL}

GONÇALVES, Marizete ${ }^{1}$

TRUCCOLO, Adriana Barni ${ }^{2}$

GONÇALVES, Marizete. TRUCCOLO, Adriana Barni. Impacto do convívio intergeracional na socialização de idosas institucionalizadas. Revista Científica Multidisciplinar Núcleo do Conhecimento. Ano 05, Ed. 10, Vol. 04, pp. 05-25. Outubro de 2020. ISSN: 2448-0959, Link de acesso: https://www.nucleodoconhecimento.com.br/educacao/conviviointergeracional

\section{RESUMO}

A institucionalização da pessoa idosa pode ser uma situação estressante uma vez que leva ao distanciamento da família e amigos e, consequentemente, ao isolamento social. Nesse contexto, o convívio com pessoas de diferentes gerações, ao mesmo tempo que propicia situações desafiadoras, proporciona troca de experiências e criação de vínculos estimulando a socialização. Dessa forma, surgiu a seguinte questão de pesquisa: Qual o impacto do convívio intergeracional na socialização entre idosas institucionalizadas e crianças? O objetivo geral é investigar o impacto provocado pelo convívio intergeracional na socialização entre idosas institucionalizadas e crianças. Foi realizado em uma instituição de longa permanência de idosos (ILPI), com 15 idosas e duas crianças. Os dados foram coletados a partir

1 Formanda em Pedagogia na Universidade Estadual do RS (UERGS).

2 Orientadora. Mestrado em Health Education (USA), Mestrado em Ciências da Saúde

- Cardiologia (FUC/RS), Especialização em Ciências do Movimento Humano (UFRGS), Educação Física (IPA). 
da observação participante e sistemática registradas em um diário de campo. A pesquisa aconteceu de março a dezembro de 2018, uma vez por semana, e contemplou dois momentos, a observação da rotina das idosas e as intervenções propriamente ditas. Foram realizadas quatro observações e vinte e cinco intervenções. Identificou-se que as atividades que mais favoreceram o convívio intergeracional foram aquelas em que as crianças explicavam às idosas, como a pintura, o desenho, e os jogos de tabuleiro. Constatou-se que sentimentos de amizade, solidariedade para com as limitações, respeito às diferenças, confiança e apego foram construídos ao longo dos meses. As idosas manifestaram maior autoconfiança e segurança, e as práticas de intervenção intergeracional promoveram momentos de aprendizagem mútuos, afastando das crianças qualquer pensamento preconceituoso a respeito da velhice. Idosas e crianças fazem parte de grupos vulneráveis, possuem rotinas, horários, e talvez esses pontos em comum as aproxime. O convívio intergeracional teve um impacto positivo sobre a socialização entre as idosas institucionalizadas e as crianças.

Palavras-chave: Idosa, criança, Instituição de Longa Permanência de Idosos, socialização.

\section{INTRODUÇÃO}

O aumento da população com idade igual ou superior a 60 (sessenta) anos é uma estatística real no mundo todo e no Brasil não é diferente. Na realidade, o processo de envelhecimento populacional no Brasil é ainda maior e mais rápido do que no resto do mundo, correspondendo a $14 \%$ do total de brasileiros, ou seja, 29,9 milhões de pessoas idosas (UNITED NATIONS, 2019).

Dentre os estados com maior proporção de idosos estão Rio de Janeiro e o Rio Grande do Sul, ambos com 18,6\% de suas populações dentro do grupo de 60 anos ou mais (AGÊNCIA IBGE NOTÍCIAS). A projeção de envelhecimento da população para o Rio Grande do Sul chegou a 207,14\% em 2019 (IBGE, 2019a). Com relação ao município de Alegrete, localizado na fronteira oeste do estado do Rio Grande do Sul, a população estimada em 2019 era de 73.589 habitantes. Destes, 11.739 eram 
de pessoas com 60 anos ou mais, sendo 5350 do sexo masculino e 6388 do sexo feminino (IBGE, 2019b).

Com relação à expectativa de vida, homens possuem uma menor expectativa de vida quando comparados com as mulheres (76,3 e 79,9 anos de idade, respectivamente) (IBGEc, 2019; GLOBAL AGE WATCH, 2014). Conforme Marcio Minamiguchi (2019), pesquisador do IBGE, a menor expectativa de vida do homem pode ser explicada por causas externas, não naturais, que atingem com maior intensidade a população masculina, tais como homicídios, acidentes de trânsito e quedas acidentais, entre outros. A esse processo damos o nome de "feminização do envelhecimento" (LINS; ANDRADE, 2018).

Parte dessas pessoas necessitam de cuidados em função da saúde debilitada, possuem vínculos familiares que não dão conta dos cuidados de que necessitam, possuem vínculos rompidos, vínculos fragilizados (FERREIRA; PREUSS, 2017; FERREIRA, 2014) ou não possuem vínculos, aumentando a demanda por instituições de longa permanência para idosos (ILPI). Sabe-se que grande parte das ILPI possui um perfil assistencialista, no qual prestar cuidados aos idosos resume-se a oferecer abrigo e alimentação (ALVES et al., 2017). O Ministério da Saúde, através da Agência Nacional de Vigilância Sanitária (ANVISA) define critérios e assegura os direitos da população idosa nas ILPIs (BRASIL, 2005).

As ILPIs são instituições governamentais e não-governamentais, de caráter residencial, na forma de domicílio coletivo para pessoas com idade igual ou superior a 60 anos, com ou sem suporte familiar (BRASIL, 2005), abrigando residentes com características de saúde distintas, portadores de problemas de saúde em condição crônica e incapacitante e nesta condição, o cuidado deve seguir a perspectiva geronto-geriátrica.

Camarano (2010) pontua que as ILPIs também têm sido denominadas como abrigos, casas de repouso e asilos, não havendo um consenso na nomenclatura, na legislação e nem na literatura. Atualmente a palavra creche vem sendo cada vez mais utilizada para designar os locais onde os idosos passam o seu tempo, seja em regime de 
internato, quando o idoso mora na instituição ou externato, quando permanecem na instituição durante o dia e voltam para a casa dos familiares à noite e finais de semana (CUNHA, 2018), surgindo como a ressignificação do asilo, cuidando o idoso tanto na sua saúde física como mental.

É necessário mencionar que a escassez de recursos e a qualificação inadequada de profissionais ou voluntários tem inviabilizado o desenvolvimento de atividades que promovam a autonomia da pessoa idosa, contribuindo para o isolamento social, e muitas vezes para a perda de identidade, da autoestima, ao estado de solidão e de recusa da própria vida, justificando a alta prevalência de doenças mentais nas ILPI (SILVA et al., 2016). Além disso, as ILPIs nem sempre conseguem atender todas as necessidades, comprometendo a qualidade de vida e bem-estar dos idosos institucionalizados (FONTES; LUCCA, 2017).

O Estatuto do Idoso no artigo 20 do capítulo $\mathrm{V}$ declara que "o idoso tem direito à educação, cultura, esporte, lazer, diversões, espetáculos, produtos e serviços que respeitem sua peculiar condição de idade" (BRASIL, 2004); sendo que, para a realização dessas atividades a pessoa idosa necessita socializar, interagir com outros, independentemente de sua idade.

Atividades em conjunto são importantes na manutenção da saúde mental melhorando aspectos cognitivos como a atenção e a memória, e o convívio com diferentes gerações pode resultar em efeitos positivos não somente para a pessoa idosa como também para crianças e adolescentes.

A participação social e a interação no fortalecimento de vínculos entre pessoas de diferentes gerações propiciam a autonomia, independência, participação, dignidade, assistência e autorrealização do idoso (MASSI et al., 2016). A convivência, a troca de ideias, o afeto e a participação de duas gerações distintas em um grupo sócio integrativo são elementos importantes para construção de vínculos sociais e afetivos.

De modo similar, Franca, Silva e Barreto (2010), salientam que o convívio dos idosos com crianças pode beneficiar mutuamente as gerações, no sentido do aprimoramento 
dos conhecimentos em relação a história familiar, a cidade onde residem, ao mundo, facilitando o estabelecimento de uma nova amizade/afetividade que desencadeie a solidariedade, e o desenvolvimento cognitivo social.

Ainda com relação à intergeracionalidade, observa-se que tem o potencial de reverter os estereótipos e avaliações negativas que os mais novos possam ter das pessoas idosas, possibilitando aos mais velhos uma maior proximidade com pessoas de outras gerações, propiciando a troca mútua dos saberes (CARVALHO, 2012).

A convivência de diferentes gerações assegura o respeito das crianças pelas gerações mais velhas, e essa interação se dá desde bebê, quando a criança é condicionada pelo adulto a conhecer objetos, fazendo dessa interação simples uma forma de descoberta do brincar, e assim, desenvolvendo seu primeiro contato social. Tal interesse segundo Tunes (2001) passa necessariamente pelo adulto, ou seja, a criança se interessa pelo brincar através da interação com o adulto. Contudo, isso vai se perdendo conforme a criança vai crescendo e interagindo com outras crianças, ou seja, a mesma faixa etária, e assim sucessivamente, perdendo o elo existente no início do seu desenvolvimento.

Villas-Boas et al. (2016) colocam que a forma de evitar preconceitos em relação à velhice é o da educação, através do contato e da convivência entre as gerações. Os autores acreditam que a antiga concepção de educação concebida como ação das velhas gerações sobre as novas, vem sendo modificada. As rápidas mudanças dos estilos de trabalho e de vida, acompanhadas por um aumento de autonomia das novas e velhas gerações, tendem a fazer da educação uma coeducação entre as gerações, alternadamente imposta e voluntária, e uma contribuição para a auto formação permanente de cada um.

As atividades lúdicas surgem como uma estratégia de incentivo à participação social proporcionando alegria e prazer, além de preencher o tempo livre das pessoas idosas institucionalizadas de forma prazerosa, aprimorando o convívio social e beneficiando aquelas com pouca mobilidade. Existem diversas atividades recreativas que não são predominantemente físicas, mas que também têm grande potencial de promoção do 
bem-estar, além de estimular cognitiva, afetiva e/ou socialmente, e estimular a livre expressão como um recurso terapêutico para o bem-estar e a melhoria da qualidade de vida (DEMO; SCORTEGAGNA, 2014).

A partir do acima exposto levantou-se a seguinte questão de pesquisa: Qual o impacto do convívio intergeracional na socialização entre idosas institucionalizadas e crianças?

Assim, o objetivo geral do trabalho foi investigar o impacto provocado pelo convívio intergeracional na socialização entre idosas institucionalizadas e crianças.

Foram objetivos específicos: Determinar os tipos de atividades que mais favorecem o convívio intergeracional; Identificar comportamentos, sentimentos e relacionamentos surgidos no desenvolvimento das atividades; Identificar os benefícios e/ou malefícios que as relações intergeracionais podem originar.

\section{PROCEDIMENTOS METODOLÓGICOS}

Demo (2010) caracteriza a pesquisa como sendo o diálogo crítico e criativo com a realidade, permitindo a quem pesquisa sentir-se capaz para intervir e ensinar. A extensão universitária, um dos elementos da trilogia universitária, juntamente com o ensino e a pesquisa é a ponte entre a universidade e o território ao qual está inserido. Nesse contexto, essa pesquisa surgiu da participação em projeto de extensão durante todo o ano de 2018, e caracterizou-se como um estudo de campo com intervenção pedagógica e abordagem qualitativa.

A pesquisa do tipo intervenção pedagógica consiste no planejamento e na implementação de interferências (mudanças, inovações), destinadas a produzir avanços, melhorias, nos processos de aprendizagem dos sujeitos que delas participam, e a posterior avaliação dos efeitos dessas interferências (DAMIANI et al., 2013).

De acordo com Moreira (2008) são características da pesquisa intervenção: a) acontecer dentro do contexto pesquisado, no caso o ILPI; b) Ser desencadeada pela 
demanda, contribuindo na solução de problemas: Houve um convite da instituição para que o projeto de extensão acontecesse na mesma; c) O pesquisador atua como mediador que articula, organiza encontros, sistematiza vozes e saberes produzidos pelos sujeitos da pesquisa, agindo num processo de escuta ativa. A acadêmica do curso de Pedagogia atuou como bolsista de extensão e pesquisadora; d) Ocorre Interação entre o pesquisador e os sujeitos da pesquisa: acadêmica, idosas e crianças; e) As Experiências cotidianas e práticas do coletivo sistematizadas, permitem descobertas e considerações teórico-metodológicas: no caso as atividades foram propostas pela acadêmica-bolsista-pesquisadora e as descobertas são descritas na seção de resultados.

Segundo Demo (2006), a pesquisa qualitativa procura preservar a realidade acima do método, buscando informação acerca da realidade e permitindo tanto sua melhor compreensão, quanto, sobretudo, condições de intervenção e mudança.

A pesquisa foi realizada em uma Instituição de Longa Permanência de Idosos (ILPI) situada na zona norte de Alegrete/RS, e tem no seu quadro de funcionários um técnico de Enfermagem, 24 funcionários e mais 02 autônomos, um médico, e um fisioterapeuta. A seleção da instituição foi intencional, visto a instituição ter convidado a orientadora da pesquisa a realizar projeto na mesma.

Quando da realização do estudo, a ILPI abrigava 35 pessoas idosas, todas do sexo feminino, com idade entre 58 anos e 102 anos de idade Das 35 idosas institucionalizadas participaram quinze (15). Também fez parte do estudo 01 (Uma) menina de 09 anos de idade e $01(\mathrm{Um})$ menino de 12 anos de idade.

Os critérios de inclusão que nortearam a participação das idosas foram: idosas com preservação da capacidade cognitiva e com condições de desenvolver atividades lúdicas, jogos de memória, pintura junto às crianças.

Os responsáveis pelas crianças assinaram termo de consentimento livre e esclarecido (TCLE) e as crianças assinaram termo de assentimento livre e esclarecido (TALE). 
As idosas acamadas, idosas que não se comunicavam verbalmente, bem como idosas com comprometimento visual e auditivo grave foram excluídas do estudo.

As idosas foram questionadas a participar das atividades, bem como se poderiam ser fotografadas. Em algumas sessões participaram, em outras se recusaram por falta de vontade, em outras questionavam se poderiam somente ficar sentadas com as crianças. Em nenhum momento insistimos para que realizassem alguma atividade em caso de recusa inicial.

Os dados foram coletados através da observação participante sistemática, de fotografias e registrados em um Diário de Campo.

De acordo com Angrosino (2009) a observação participante refere-se à observação que acontece com o pesquisador desempenhando um papel ativo no contexto observado.

Na observação sistemática, direta ou estruturada é requerido que se defina o conjunto de comportamentos a ser observado, o momento adequado e a forma de registro dos dados obtidos (VERGARA, 2012). No caso desta pesquisa, a forma de registro foi a fotografia, os comportamentos observados foram alegria/tristeza; entusiasmo/apatia e o momento da observação foi antes da atividade e após a atividade. As imagens auxiliam na composição da escrita, realizando uma análise mais contextualizada sobre as observações. Para mais, a foto registra detalhes que não foram percebidos no momento observado e podem ser analisados mais detidamente conforme a necessidade.

A pesquisa realizada de março a dezembro, uma vez por semana, no turno da tarde, entre $14 \mathrm{~h}$ e $17 \mathrm{~h}$ contemplou dois momentos, a observação da rotina das idosas e as intervenções propriamente ditas.

No total foram realizadas quatro observações, vinte e cinco intervenções e reuniões com a orientadora da pesquisa para a avaliação e análise das intervenções. 
Por questões éticas o nome das participantes foi preservado, e a instituição não colocou restrição na divulgação do nome.

Assim, as atividades propostas em cada encontro bem como os comportamentos observados das idosas a essas atividades e à aproximação e socialização com as crianças foram fotografadas e registradas no Diário de Campo da pesquisadora.

O Diário de Campo, segundo Minayo (2012, p. 71) "nada mais é do que um caderninho, uma caderneta, ou um arquivo eletrônico no qual escrevemos todas as coisas que não fazem parte do material formal de entrevistas em suas várias modalidades".

Para Lewgoy e Arruda (2004, p. 123-124), o Diário de Campo, consiste em um instrumento capaz de possibilitar "o exercício acadêmico na busca da identidade profissional" sendo que, através de aproximações sucessivas e críticas, pode realizar uma "reflexão da ação profissional cotidiana, revendo seus limites e desafios". Assim, o registro e o detalhamento dos encaminhamentos no diário de campo propiciam um constante revisitar dos dados, o que contribui para ampliar as ações de modo a aproximá-las da resolutividade da demanda.

Algumas das falas das idosas que impactaram a pesquisadora também foram registradas no Diário de Campo.

Cabe mencionar, que segundo Piaget, as crianças estão no período operatório, caracterizado pelo desenvolvimento da lógica e dos sentimentos normativos e ideais, é subdivido em operatório concreto e operatório formal, devido às diferenças importantes no desenvolvimento do pensamento lógico e na afetividade. No período das operações concretas (7 aos 11 - 12 anos), o egocentrismo intelectual e social (incapacidade de se colocar no ponto de vista de outros) que caracteriza o período pré-operatório, dá lugar à capacidade da criança em estabelecer relações e coordenar pontos de vista diferentes (próprios e de outrem ) e de integrá-los de modo lógico e coerente (RAPPAPORT, 1981). Também importante neste estágio é o aparecimento da capacidade da criança de interiorizar as ações, ou seja, ela começa a realizar 
operações mentalmente e não mais apenas através de ações físicas típicas da inteligência sensório-motora. Muito importante ao propósito dessa pesquisa com idosas é o avanço na conduta da criança em atividades em grupo. A capacidade de concentração quando a criança se engaja numa atividade individual, e a cooperação nos trabalhos em grupos conseguindo colaborar com o outro já são identificados. Ainda no que se refere às relações sociais, a criança já se engaja no jogo coletivo, e influenciada pela motivação de ganhar, começa a compreender a importância das regras para garantir a igualdade de condições (PIAGET, 1947-2005).

Quando pensamos em crianças brincando com pessoas idosas nos vêm à mente Borba (2007), quando o mesmo diz que através do brincar a criança inventa e realiza ações e interações sendo autora de suas histórias e podendo ser pai, mãe, transitando por outros tempos e lugares. Essa capacidade da criança pode transportar as idosas para outros lugares também, mais alegres e coloridos do que o atual.

O estudo, o planejamento responsável, a intervenção, o questionamento e a análise foram ações constantes neste processo. Havia idosas e crianças "em jogo", sentimentos, sensações, interações acontecendo. Nesse processo investigativo não existiu intenção nem possibilidade de uma análise sem distanciamento.

Na seção de resultados, a seguir, as idosas serão referidas como "as vovós". Não se tem como fazer de outra forma, pois a palavra idosa remete a um distanciamento que a pesquisadora não teve intenção de ter desde o início. Durante todo o processo nos propusemos a um salto em queda livre, com a mente aberta para aceitar o que fosse sendo revelado e sem nunca antecipar, prever ou considerar já saber algo.

\section{RESULTADOS E DISCUSSÃO}

A análise do material coletado deu-se em etapas: Na primeira etapa, de posse das anotações do diário de campo, reviveu-se cronologicamente os eventos, relembrando e reconstruindo mentalmente os comportamentos observados antes das intervenções. Os semblantes, os olhares, o que parecia ser alegria, o que parecia ser tristeza, o que nos remetia a apatia, o que nos remetia a entusiasmo. 
$\mathrm{Na}$ segunda etapa, analisou-se quais as intervenções que mais favoreceram o convívio intergeracional, e que pareceram mais significativas para as vovós e para as crianças; Quando percebemos mais sorrisos? Quando houve mais interação vovó e criança? Entre vovó e vovó? O que mais gostaram de fazer? O que menos gostaram de fazer? Procurou-se reconhecer comportamentos, sentimentos e relacionamentos surgidos no desenvolvimento das atividades. E, por fim, identificou-se potenciais benefícios e/ou malefícios que a relação intergeracional provocou.

\subsection{ETAPA 1: AS OBSERVAÇÕES}

Os primeiros dias foram dedicados a aproximação com as idosas. Para isso foram realizadas quatro observações com o intuito de conhecer a rotina das vovós, e de familiarizá-las com a pesquisadora e com as crianças.

A rotina no turno da tarde, após o almoço, consistia em encaminhar as idosas para uma sala com televisão, onde permaneciam sentadas olhando para a rua ou assistindo televisão sem socializarem ou realizar alguma atividade lúdica. Às $16 \mathrm{~h}$ as vovós iam para o refeitório fazer o lanche da tarde. A textura do alimento não era a mesma para todas: pastoso, líquido e até mesmo o recurso de seringas para outras se fazia necessário para que algumas vovós pudessem engolir aos poucos.

Neste período houve interação com algumas idosas, e percebeu-se carência, tristeza e ao mesmo tempo inquietação no olhar e na postura de algumas. No percurso da sala de televisão até o refeitório passa-se pelos quartos. Cada quarto com duas camas, algumas ocupadas por vovós debilitadas. A instituição possuía até o final da pesquisa duas centenárias e uma vovó residente a mais de vinte anos na instituição.

Nas duas últimas observações a pesquisadora levou as crianças, receosa de que pudessem se sentir entediadas e que não quisessem retornar. Gostaram de ir e pediram para voltar.

$\mathrm{Na}$ última observação a aproximação com as vovós foi maior, sendo mencionado que o projeto tinha como foco principal a realização de atividades conjuntas entre as vovós 
e as crianças. As mesmas, mostraram-se muito interessadas e dispostas a interagir com as crianças, foram muito receptivas demostrando entusiasmo na presença das crianças e da pesquisadora.

\subsection{ETAPA 2: AS INTERVENÇÕES}

Ao longo dos 25 encontros, pensou-se em atividades em que as crianças pudessem elas mesmas propor e explicar às vovós. Normalmente o que acontece são os mais velhos ensinarem aos mais jovens, e isso não precisa ser regra. Essa iniciativa visou estimular a postura autônoma e desenvolver o senso de responsabilidade da criança.

As intervenções foram divididas em eixos temáticos: Arte Expressiva: Desenho, Argila e Pintura; Jogos de Tabuleiro e Artesanato; Música, Dança e Leitura; Passeio, Beleza e Autocuidado.

\subsubsection{EIXO TEMÁTICO ARTE EXPRESSIVA: PINTURA, DESENHO E ARGILA}

A pintura em bandejas de isopor foi uma atividade proposta por Lorran (12 anos de idade), e a Lahine (09 anos de idade) e que foi muito apreciada pelas vovós. As idosas fizeram lindamente as pinturas na bandeja de isopor, algumas mais e outras menos detalhistas, contudo, todas estavam empolgadas em realizar a atividade com capricho. De acordo com Fortuna (2005) a pintura e o desenho ajudam a reconciliar conflitos emocionais, além de auxiliar na autopercepção e no desenvolvimento do indivíduo. A pintura estimula a criatividade, a sensibilidade e aumenta a capacidade de concentração e expressão das vovós e das crianças, além de trabalhar a motricidade fina (FORTUNA, 2000; FORTUNA, 2004). É uma atividade social que transmite uma sensação de bem-estar psicológico e permite melhora da autoestima, onde o sujeito permite a quem observa o contato com suas emoções, suas sensações, sentimentos e imagens do seu mundo interior (CARVALHO, 1995).

Ainda no eixo temático arte expressiva, o desenho desenvolve a esfera cognitiva, além da capacidade de abstração (GUEDES; GUEDES; ALMEIDA, 2011). A atividade foi 
realizada no dia de aniversário de uma das vovós, a Joana. Sabíamos do aniversário pois pedimos no primeiro dia de observação a lista com as datas de nascimento para fazermos um mural de aniversários. Nesse dia Joana estava bem, já faziam duas sessões que não participava. Joana tem esquizofrenia, mas em nenhum momento a doença impediu que mantivesse um bom relacionamento com as crianças. Notamos que ninguém sabia do aniversário e na sessão seguinte fizemos o mural de aniversários.

Cantamos parabéns e the abraçamos com muito carinho. Participaram com dedicação da atividade, mesmo sendo um material simples de pintura. Conversamos bastante $\mathrm{e}$ foi muito tranquila à tarde com elas. Demoramos a ir embora, o ambiente estava muito agradável, elas socializaram mais entre elas e percebemos que a cada semana nossos laços de afeto se estreitavam.

A intervenção foi muito satisfatória. Nesse dia uma das enfermeiras mencionou que as vovós já nos aguardavam ansiosas, querendo saber a que horas iríamos chegar, e que depois de irmos embora, ficavam relaxadas e tranquilas. Nesse dia, percebemos estar no caminho certo, que nosso trabalho estava fazendo diferença na vida delas e foi muito gratificante. Cada intervenção era uma descoberta e troca de experiência.

A construção de vínculos e fortalecimento dos laços afetivos, tão importante para as idosas quanto para o desenvolvimento integral das crianças só é possível quando ocorre interação entre os grupos. Para potencializar essas vivências intergeracionais devemos perceber o que as crianças e os adultos revelam, através da linguagem, do olhar, dos gestos, e de todas as formas de comunicação. São com as interações com os espaços e com o outro que as intenções são reveladas. (EDWARDS; GANDINI; FORMAN, 1999).

A argila foi utilizada com o propósito de construir uma máscara. A intenção era mostrar que elas eram capazes de criar algo partir de um material nada sugestivo. Teriam de usar a imaginação, ter criatividade, estaríamos estimulando a criação artística e contribuindo para fortalecer a autoestima das vovós. 
Aceitaram o desafio estimuladas pela Lahine e pelo Lorran. Sentíamos que as crianças levaram "vida" àquelas idosas. As crianças iam de um lado para outro ajudar. Quem diria que os dois iriam se acostumar tão rapidamente com um local sem outras crianças, pelo contrário, com pessoas de idades tão opostas, algumas com limitações físicas, pouca mobilidade. Quem diria que iriam se apegar aquelas pessoas que nunca haviam visto anteriormente. E a recíproca havia se tornado verdadeira.

A argila foi trabalhada em duas sessões. Na primeira foi feito o molde da máscara e na segunda intervenção a pintura. Foi uma das atividades mais gratificantes pois as vovós ficaram deslumbradas com o que criaram. Ao final fizemos uma exposição das máscaras e as participantes se mostravam muito orgulhosas. A modelagem possibilita a estimulação tátil, o trabalho muscular, a estrutura postural, bem como a capacidade de expressão e de planejamento (GUEDES; GUEDES; ALMEIDA, 2011).

Carvalho (2012) diz que "o uso da arte como terapia implica um processo criativo que pode ser um meio tanto de reconciliar conflitos emocionais, como de facilitar a autopercepção e o desenvolvimento pessoal". Nessa atividade as vovós perceberam que não eram mais as mesmas vovós que ficavam na sala de televisão olhando para o nada boa parte da tarde. Estavam empolgadas com aquela máscara, com as cores escolhidas, e com elas próprias. Abaixo, alguns registros da atividade.

\subsubsection{EIXO JOGOS DE TABULEIRO E ARTESANATO}

No eixo artesanato foi proposto para as vovós que utilizassem palitos de picolé para fazerem um porta objeto. Os palitos seriam colados com cola quente e após a finalização da caixa, a mesma seria pintada. A intenção foi trabalhar a atenção, coordenação motora fina e aumento do autoconceito das vovós (ao darem-se conta de que são capazes de construir algo útil a partir de material tão simples). Os resultados fizeram emergir melhora no autoconceito das idosas demonstrada quando do orgulho com que exibiam sua produção para as funcionárias da instituição e para outras idosas. Santos e Pavão (2014) referem os trabalhos manuais como "uma forma de liberdade de expressão e criatividade, auxiliando na prevenção de depressão e de outras doenças emocionais". Guedes; Mota e Almeida (2011) ratificam ao defender 
que as tarefas manuais expressam as potencialidades dos idosos, "organizando seu relacionamento consigo mesmo, com o outro e o mundo".

Todos os jogos de tabuleiro foram confeccionados pelas vovós para que depois usufruíssem de suas produções. No Tabuleiro das Cores, as vovós, inicialmente pintaram uma caixa de ovos nas cores verde, vermelho, amarelo, azul e branco. Após, deveriam colocar tampinhas com a cor correspondente no tabuleiro.

Com o Tabuleiro das Formas Geométricas, (TFG) as idosas, primeiramente irão colar as formas geométricas no papel EVA (Etil Vinil Acetato), para depois jogar, combinando as formas geométricas de acordo com as que se encontram no tabuleiro.

Os jogos de tabuleiro são importantes para as pessoas idosas à medida que exercitam "movimentos motores finos, a capacidade de usar nossas mãos e dedos, e de desempenhar movimentos delicados envolvendo controle preciso" (GARDNER, 1994, p. 163). Além disso, os jogos de mesa, como atividades de lazer ativo, auxiliam para retardar os efeitos negativos do processo natural de envelhecimento, por oportunizarem "situações que incentivam a autonomia do idoso, através de estímulos sensoriais, mentais e motores, além de serem atividades que proporcionam o convívio social” (LOPES, 2009).

No jogo da correspondência as idosas confeccionaram cartões, alguns com números, e outros com desenhos em quantidades correspondentes aos números desenhados. A tarefa era combinar o cartão com número com o cartão contendo a respectiva quantidade de objetos.

No jogo da memória as vovós jogaram em duplas. Além de propiciar a socialização, o jogo desenvolve a localização espacial e estimula o raciocínio. Camargo e Cid (2000) relatam que a "memória espacial possibilita ao indivíduo mediante a lembrança identificar a posição de um determinado objeto no espaço".

Segundo Grieve (2005), a exploração do mundo ao nosso redor decorre da memória espacial, já que esta retém informações que vêm do ambiente em poucos segundos, recuperando-as posteriormente na memória de longo prazo, com o objetivo de, no 
trajeto, possuir uma sequência de movimentos. Contribuem para esta "exploração do mundo a atenção, o reconhecimento visual, as percepções visuais e tácteis". Uma atividade também apreciada pelas vovós foi o jogo de ligar os números. Foram distribuídas folhas A4 com os números dispostos ao longo da folha. Na medida que os números eram ligados em ordem crescente formava-se um desenho que posteriormente seria colorido pelas vovós. O objetivo era estimular a atenção e declínio cognitivo.

\subsubsection{EIXO TEMÁTICO MÚSICA, DANÇA E LEITURA}

Com intuito de possibilitar momentos de descontração e socialização bem como desenvolver o raciocínio e a memória realizamos a seguinte dinâmica: foi passado um balão cheio para as idosas e foi cantada uma parlenda enquanto elas passavam o balão de uma para outra. No momento em que terminavam de cantar a parlenda, a idosa que estivesse com o balão lia uma estrofe de uma poesia da Cecília Meirelles, que estava exposta na mesa. A seguir, entregamos folhas brancas A4, tintas guache, lápis de cor, lápis e pinceis para as vovós fazerem a ilustração e releitura da poesia preferida. As vovós tiveram certa dificuldade em realizar a leitura das poesias e tiveram ajuda. Essa atividade não foi mais repetida pois sentimos que algumas idosas se sentiram constrangidas pela dificuldade na leitura e escrita. Desenharam riscos e outra tentou desenhar letras aleatórias.

\section{Colar de Carolina}

Com seu colar de coral, Carolina corre por entre as colunas da colina. O colar de Carolina colore o colo de cal, torna corada a menina. E o sol, vendo aquela cor do colar de Carolina, põe coroas de coral nas colunas da colina.

\section{Cecília Meirelles}

A dança aconteceu quando foi realizada uma festa Junina. Algumas vovós pareceram mais animadas, outras não quiseram dançar. O estudo de Oliveira et al. (2010) sobre a influência que os bailes exercem em idosos institucionalizados, encontrou que "a dança, minimiza as repercussões fisiológicas do envelhecimento e auxilia na 
independência, manutenção do equilíbrio, interação social, melhora do condicionamento físico e, consequentemente, da qualidade de vida, e do estado psicológico".

\subsubsection{EIXO TEMÁTICO PASSEIO, BELEZA E AUTOCUIDADO}

O fim do ano, e consequentemente do projeto estava chegando e pensamos em dedicar as últimas sessões a brincadeiras diversas, a um passeio e a um dia de spa para as vovós. Nossa intenção era promover momentos de relaxamento corporal, interação, socialização, contribuir para o fortalecimento da autoestima e estimular a percepção dos sentidos. Foi convidada uma massagista, para voluntariamente, realizar massagens nas vovós. Emili aceitou e levou consigo dois colegas. Nesse dia, uma bola e um bambolê foram utilizados para trabalhar a mobilidade das mãos. As idosas receberam bem os voluntários que proporcionaram algumas horas de relaxamento e descontração. Foi uma experiência gratificante para todas, mas uma certa angústia começava a tomar conta de mim (peço licença ao leitor para apoderarme dessa parte do texto e redigi-lo na primeira pessoa. Não consigo imaginar outra forma de escrita nesse momento, pois conforme me aproximo do final deste texto, sinto que estou apegada a ele, revivi emoções, redescobri sentimentos que já estavam adormecidos e que agora transbordam).

Em nosso último encontro fomos passear de Maria fumaça, um misto de felicidade e tristeza tomou conta de mim. Felicidade por ver nos olhos, no sorriso e nos gestos daquelas idosas a excitação, a empolgação, por sentir que estavam se sentindo vivas. Tristeza porque o fim do ano estava chegando e com ele o projeto e a pesquisa. E agora?

Estávamos apegadas aquelas pessoas e elas a nós. As crianças como ficariam? A interrupção de uma convivência semanal de um ano dar-se de uma hora para outra deixaria marcas nas vovós e nas crianças? Propusemos um passeio e a direção da instituição concordou. Desejava promover um passeio divertido para as vovós e organizamos em um sábado pela manhã, uma volta pela cidade de Maria Fumaça. O proprietário gentilmente atendeu ao nosso pedido e não cobrou pelo passeio. A 
maioria das vovós não saia da instituição há anos. Achavam tudo bonito e diferente, não sabiam para onde olhar. Nesse dia percebi a responsabilidade de levá-las para a rua e sobre todas as atividades que havia trabalhado com elas. Estávamos, eu e as crianças, e indiretamente a orientadora do trabalho, fazendo a diferença na vida dessas pessoas.

No último mês as crianças foram em semanas intercaladas para que tanto as vovós quanto elas não sentissem tanto o impacto da ausência que umas fariam às outras. As práticas de intervenção intergeracional promoveram momentos de aprendizagem mútuos, normalizando o convívio entre criança e idosa, afastando qualquer preconceito a respeito da velhice.

\section{CONSIDERAÇÕES FINAIS}

O convívio intergeracional entre a bolsista, crianças e as idosas propiciou a ampliação do papel social e educativo da pedagogia, oportunizando a interação e convivência na ILPI através da educação não formal.

Identificou-se que as atividades que mais favoreceram o convívio intergeracional foram aquelas em que as crianças explicavam às idosas, como a pintura, o desenho, e os jogos de tabuleiro.

Constatou-se que sentimentos de amizade, solidariedade para com as limitações, respeito às diferenças, confiança e apego foram construídos ao longo dos meses. Lahine criou afinidade com a dona Nercy e o Lorran com a dona Cleir e dona Tereza.

As idosas se mostraram mais autoconfiantes, seguras, abertas a novidades, e as práticas de intervenção intergeracional promoveram momentos de aprendizagem mútuos, afastando das crianças qualquer pensamento preconceituoso a respeito da velhice.

O trabalho pedagógico na educação não formal tem um papel educativo e social. Preocupa-se com a melhoria das relações interpessoais e da qualidade de vida, 
permite a participação ativa em sociedade, e o desenvolvimento real dos sujeitos independentemente da idade, desmistificando estereótipos de grupos vulneráveis.

Idosas e crianças fazem parte de grupos vulneráveis, possuem rotinas, horários e talvez esses pontos em comum as aproxime. O que se pode dizer é que o convívio intergeracional teve um impacto positivo sobre as idosas institucionalizadas e sobre as crianças.

A sociedade precisa ser mais inclusiva e solidária. As pessoas precisam se importar mais umas com as outras, porque as redes de relacionamento são muito importantes. São elas que vão garantir cuidado, interação, diminuir o isolamento social. Tudo isso tem um impacto muito positivo na saúde do idoso.

Qualquer resposta de saúde pública ao envelhecimento da população deve passar pela abordagem da discriminação etária. Sabe-se que estereótipos baseados em idade influenciam comportamentos, e combater a discriminação à pessoa idosa, mesmo que desafiador pode modificar atitudes e comportamentos. Para que isso ocorra compete envolver todas as gerações para uma nova compreensão acerca do envelhecimento que não se baseie em conceitos ultrapassados de que as pessoas idosas são um fardo, e sim pessoas com ampla diversidade de experiências que podem ser transmitidas, através da integração, da socialização e da valorização de suas vivências (OMS, 2015).

\section{REFERÊNCIAS}

AGÊNCIA IBGE NOTÍCIAS. 2018.2 Disponível em: $\quad$ https://agenciadenoticias.ibge.gov.br/agencia-noticias/2012-agencia-denoticias/noticias/20980-numero-de-idosos-cresce-18-em-5-anos-e-ultrapassa-30milhoes-em-2017. Acesso em 24 de julho de 2020.

ALVES, Manuela Bastps; Menezes, Maria do Rosário; DIAS Ridalva Martins; ALMEIDA Valdenir da Silva; AMARAL, Juliana Bezerra. Instituições de longa permanência para idosos: aspectos físico-estruturais e organizacionais. Escola. Anna 
Nery Revista de Enfermagem, vol. 21, núm. 4. 2017. p. 1-8. Disponível em: https://www.redalyc.org/articulo.oa?id=127752022014. Acesso em 18/04/2019.

ANGROSINO, Michael. Etnografia e observação participante. Porto Alegre: Artmed, 2009.

BALLA, Eliane; Scortegagna, Helenice de Moura. Uso do tempro livre através de recursos expressivos: contribuição para um grupo de idosos institucionalizados. Estudos interdisciplinares do envelhecimento. Porto Alegre: v. 19, n. 2, p. 471-484., 2014.

BRASIL. Estatuto do idoso: lei federal no 10.741, de 01 de outubro de 2003. Brasília, DF: Secretaria Especial dos Direitos Humanos, 2004. Disponível em: www.planalto.gov.br/ccivil_03/leis/2003/L10.741.htm. Acesso em 30/04/2020.

BRASIL. Ministério da Saúde - MS, Agência Nacional de Vigilância Sanitária ANVISA. RESOLUÇÃO DE DIRETORIA COLEGIADA - RDC № 283, DE 26 DE SETEMBRO DE 2005.2 Disponível http://bvsms.saude.gov.br/bvs/saudelegis/anvisa/2005/res0283_26_09_2005.html. A cesso em 10/08/2020.

BORBA, Angela. A brincadeira como experiência de cultura na educação infantil. Revista criança do professor de educação infantil. Brasília: Ministério da Educação, Secretaria de Educação Básica, 2007.

CAMARANO Ana Amélia. Cuidados de longa duração para a população idosa : um novo risco social a ser assumido? Rio de Janeiro: Ipea, Instituto de Pesquisa Econômica Aplicada. 2010. 350 p. : Disponível em: http://www.ipea.gov.br/portal/images/stories/PDFs/ivros/livro_cuidados.pdf. Acesso em 18/04/2019.

CAMARGO, Cândida; CID, Carla. Habilidade Viso-Espaciais. In FORLENZA, Orestes Vicente e CARAMELLI, Paulo (Ed.), Neuropsiquiatria Geriátrica. São Paulo: Atheneu. p.531-537, 2000. 
CARVALHO Maria Margarida. A arte cura? Recursos artísticos em psicoterapia. Campinas: Editoria Psy II. 1995.

CARVALHO, Maria Clotilde Barbosa Nunes Maia de. Relações Intergeracionais Alternativa para minimizar a exclusão social do idoso. Revista Portal de Divulgação. 2012: n.28. Ano III. Dez. Disponível em: http://www.portaldoenvelhecimento.org.br/revista/index.php. Acesso em 30/04/2019.

CUNHA, Angélica Rangel do Nascimento. Creche Para Idosos: Um Novo Campo de Atuação para Pedagogos. Revista Científica Multidisciplinar Núcleo do Conhecimento. Ano 03, Ed. 04, Vol. 05, pp. 107-118. 2018.

DAMIANI, Magda Floriana; ROCHEFORT, Renato Siqueira; CASTRO, Rafael Fonseca; DARIZ, Marion Rodrigues; PINHEIRO, Sílvia Siqueira. Discutindo pesquisas do tipo intervenção pedagógica. Cadernos de Educação (UFPel). Vol 45, p. 57-67. 2013

Disponível

em:

https://periodicos.ufpel.edu.br/ojs2/index.php/caduc/article/view/3822. Acesso em $12 / 07 / 2020$

DEMO, Pedro. Pesquisa e informação qualitativa: Aportes metodológicos. Campinas: São Paulo. Papirus, 3a edição, 2006. Disponível em: https://goo.gl/RgmwEp. Acesso em: 13/05/2019.

DEMO, Pedro. Desafios modernos da educação. Petrópolis: Vozes, 2010.

FERREIRA, Patrícia Antunes. Qualidade de vida nas Instituições de Longa Permanência para idosos no Estado de Minas Gerais. 2014. Disponível em: www.mp.mg.gov.br/portal/public/interno/arquivo/id/7191. Acesso em 25/07/2020.

FERREIRA, Hyara; PREUSS, Lislei Teresinha. Motivos que levam as famílias e as pessoas idosas buscarem por vaga em Instituição de Longa Permanência para Idosos no Município de Ponta Grossa - Paraná. II Congresso Internacional de Política Social e Serviço Social: desafios contemporâneos. III Seminário nacional de território e gestão de políticas sociais. II Congresso de direito à cidade e justiça 
ambiental. Londrina PR, de 04 a 07 de Julho de 2017. Disponível em: https://www.congressoservicosocialuel.com.br/anais/2017/assets/131577.pdf. Acesso em: 02/04/2020.

FONTES, Rhayda Melissa Souza; LUCCA, lula Lamounier. A importância de um evento recreativo para idosos institucionalizados. Rev. Ciênc. Ext. v.13, n.2, p.60-70, 2017. Disponível em: http://ojs.unesp.br/index.php/revista_proex/article/view/1208/1374. Acesso em 23/03/2019.

FORTUNA, Sonia Maria Castelo Branco. Terapias expressivas. Campinas: Editora Alínea; 2000.

FORTUNA, Sonia Maria Castelo Branco. Doença de Alzheimer, qualidade de vida e terapias expressivas: arteterapia. Campinas: Alínea; 2005.

FORTUNA, Tânia Ramos. Vida e morte do brincar. In: ÁVILA, Ivany Souza; SEFTON, Ana Paula (orgs.). Escola e sala de aula - mitos e ritos: um olhar pelo avesso do avesso. Porto Alegre: 2004. p. 47-59.

GARDNER, Howard. Estruturas da mente : a teoria das inteligências múltiplas. Porto Alegre: Artes Médicas Sul, 1994, 304 p.

GLOBAL AGE WATCH. 2014. Disponível em: https://www.helpage.org/globalagewatch/population-ageing-data/infographic-older-women/. Acesso em: 20/07/2020.

GRIEVE, June. Neuropsicologia em Terapia Ocupacional - Exame da Percepção e Cognição. São Paulo: Editora Santos, 2005.

GUEDES, Maria Helena Mota; GUEDES, Helisamara Mota; ALMEIDA, Martha Elisa Ferreira. Efeito da prática de trabalhos manuais sobre a autoimagem de idosos. Revista Brasileira de Geriatria e Gerontologia, 14(4), 731-742, 2011. Disponível em: http://www.scielo.br/pdf/rbgg/v14n4/a12v14n4.pdf. Acesso em 1\%/08/2020. 
IBGE.

Censo

Demográfico,

2019a.

Disponível

em: https://cidades.ibge.gov.br/brasil/rs/alegrete/panorama. Acesso em: 07 de abril de 2020.

IBGE. Instituto Brasileiro de Geografia e estatística, 2019 b [online]. Disponível em: https://cidades.ibge.gov.br/brasil/rs/panorama. Acesso em: 03 de dezembro de 2019.

IBGE. Expectativa de vida dos brasileiros aumenta para 76,3 anos em 2018. 2018. Disponível em: https://agenciadenoticias.ibge.gov.br/agencia-noticias/2012-agenciade-noticias/noticias/26103-expectativa-de-vida-dos-brasileiros-aumenta-para-76-3anos-em-2018./ Acesso em: 23/07/2020.

IBGE, Censo Demográfico, 2019d. Disponível em: http://cidades.ibge.gov.br/. Acesso em: 03/12/2019d.

LEWGOY, Alzira Baptista; ARRUDA, Maria. Novas tecnologias na prática profissional do professor universitário: a experiência do diário digital. Revista Textos e Contextos: coletâneas em Serviço Social. Porto Alegre: EDIPUCRS, n. 2, p. 115130, 2004

LINS, Isabella Lourenço; ANDRADE, Luciana Vieira Rubim. A feminização da velhice: representação e silenciamento de demandas nos processos conferencistas de mulheres e pessoas idosas. Mediações. Londrina, V. 23 N. 3, P.436-465. 2018. Disponível em http://www.uel.br/revistas/uel/index.php/mediacoes/article/view/34289 Acesso em 13/07/2020.

LOPES, Ludmila Mara Banks Ferreira. Jogos de mesa para idosos: análise e considerações. São Paulo, 2009. 160 p. il. Dissertação (Mestrado - Área de Concentração: Projeto, Espaço e Cultura) - FAUUSP.

MASSI, Aline Romão; BERBERIAN, Ana Paula; ZIESEMER, Nadine. Impacto de atividades dialógicas intergeracionais na percepção de crianças, adolescentes e idosos. Revista CEFAC [internet], vol. 18, núm. 2, p. 399-407. 2016. Instituto Cefac 
São Paulo, Brasil. Disponível em: http://www.scielo.br/pdf/rcefac/v18n2/1982-0216rcefac-18-02-00399.pdf. Acesso em: 23/03/2019.

MINAYO, Maria Cecília de Souza. O desafio da pesquisa social. In: Minayo. Pesquisa social: teoria, método e criatividade. Rio de Janeiro: Vozes. 2012. p. 9-29.

MORAES, Edgar Nunes. Atenção à saúde do Idoso: Aspectos Conceituais. / Edgar Nunes de Moraes. Brasília: Organização Pan-Americana da Saúde. 2012. 98 p.: il.

MORAGAS, Ricardo Moragas. Gerontologia social: envelhecimento e qualidade de vida. São Paulo, SP: Paulinas, 1997.

MOREIRA, Maria Ignez Costa. Pesquisa-intervenção; especificações e aspectos da interação entre pesquisadores e sujeitos da pesquisa. In: CASTRO L.R.; e BESSET, V.L. (Orgs.) Pesquisa-interação na infância e na juventude. NAU: Rio de Janeiro, 2008.

OLIVEIRA, Raphael Gonçalves; MADRUGA, Vera Aparecida; VERLENGIA, Rosangela; TOLOCKA, Rute. Características pessoais e participação em bailes numa instituição de longa permanência para idosos. Revista Brasileira de Cineantropometria e Desempenho Humano. v 12, n.4, 295-301, 2010.

ORGANIZAÇÃO MUNDIAL DA SAÚDE. OMS. Relatório Mundial de envelhecimento e saúde. 2015. Disponível em: http://apps.who.int/ Acesso em: 30/04/2019.

PAIVA, Vanilda. Educação Permanente: ideologia educativa ou necessidade econômico-social? In: PAIVA, Vanilda. RATTNER, Henrique. Educação permanente e capitalismo tardio. São Paulo: Cortez, p. 7 -63, 1985.

PALMEIRÃO, Cristina; MENEZES, Isabel. A interação geracional como estratégia educativa: um contributo para o desenvolvimento de atitudes, saberes e competências entre gerações. A Animação Sociocultural na Terceira Idade (pp. 22-35). 2009. Disponível em: 
https://repositorio.ucp.pt/bitstream/10400.14/3961/1/FEP_Palmeir\%C3\%A3o_Cristin a-dig3.pdf. Acesso em: 28/04/2019.

PIAGET, Jean. A representação do mundo na criança: com o concurso de onze colaboradores. Tradução Adail Ubirajara Sobral (Colaboração de Maria Stela Gonçalves). Aparecida: Ideias \& Letras, 1947/2005.

RAPPAPORT, Clara Regina. Modelo piagetiano. In RAPPAPORT; FIORI; DAVIS. Teorias do Desenvolvimento: conceitos fundamentais. Vol. 1. 1981. p. 5175.

SANTOS, Jessica Rodrigues; PAVÃO, Yeda. (2014). Empreendedorismo social: Estudo em uma instituição de Longa Permanência para Idosos (ILPI). IX EPCTEncontro de Produção Científica e Tecnológica Campo Mourão. Disponível em: http://www.fecilcam.br/nupem/anais_ix_epct/PDF/TRABALHOSCOMPLETO/AnaisCSA/21.pdf. Acesso em: 02/08/2020.

SILVA, Mariluce Rodrigues; Santos natália Prates Vieira; Santos Rafaela Almeida; Cunha, Genilton Rodrigues. A percepção do idoso institucionalizado sobre os benefícios das oficinas terapêuticas. Revista Brasileira de Promoção da Saúde, Fortaleza: 29(Supl): 76-84. 2016.

TUNES, Elizabeth; TUNES, Gabriela. O Adulto, a Criança e a Brincadeira. Em Aberto. Brasília: v. 18, n. 73, p. 78-88, jul. 2001.

United Nations, Department of Economic and Social Affairs, Population Division (2019). World Population Prospects 2019: Methodology of the United Nations population estimates and projections. Disponível em https://population.un.org/wpp/Publications/Files/WPP2019_Methodology.pdf Acesso em 14/08/2020.

VERGARA, Sylvia Constant. Métodos de coleta de dados no campo. 2. Ed. São Paulo: Atlas. 2012. 
VILLAS-BOAS Susana; OLIVEIRA Albertina Lima; RAMOS Natália; MONTERO Inmaculada. A educação intergeracional no quadro da educação ao longo da vida Desafios intergeracionais, sociais e pedagógicos. Investigar em Educação - II a Série. Número 5, 2016.

Enviado: Setembro, 2020.

Aprovado: Outubro, 2020. 